\title{
Asthma severity at night during recovery from an acute asthmatic attack
}

\author{
E W Hoskyns, D M Heaton, C S Beardsmore, H Simpson
}

\begin{abstract}
This study was undertaken to investigate the severity of night time asthma in children in hospital recovering from an acute attack of asthma. Twenty two children aged 5-14 years were studied. Coughing 'epochs' overnight varied from one to 156 (median 39.5) and mean overnight arterial oxygen saturation $\left(\mathrm{SaO}_{2}\right.$ ) from 82 to $98 \%$ (mean 91-3). $\log _{e}$ values for cough showed a correlation with $\mathrm{SaO}_{2}$. An $\mathrm{SaO}_{2}$ of $<90 \%$ was invariably associated with coughing but $\mathrm{SaO}_{2}$ above 95\% did not preclude cough. Peak flow measured in the morning or evening correlated with $\mathrm{SaO}_{2}$ but not with $\log _{e}$ cough, and clinical examination scores showed no correlation with overnight measurements. Night time $\mathrm{SaO}_{2}$ correlated better with daytime tests of lung function than $\log _{e}$ cough. In general, night time indices of severity reflected daytime pulmonary function status but night cough was sometimes prominent in less severely affected cases. At the time of discharge, clinical indices of severity underestimated the degree of functional impairment at night.
\end{abstract}

Nocturnal symptoms, especially cough, are common and sometimes dominant features of asthma in children. Control of symptoms tends to deteriorate at night ${ }^{1}$ and in adult asthmatics respiratory crises and death are more common at this time. ${ }^{2} 3$

In children, nocturnal symptoms are often under reported, ${ }^{4}$ suggesting that night time morbidity may be underestimated. In a study of asthmatic children with prominent nocturnal symptoms, Thomson et $a l^{5}$ demonstrated that cough is most frequent during the two hours after retiring and again before getting up in the morning, and not betwen 3 and 5 am when peak flow is lowest. ${ }^{6}$ This has led to speculation about the relationship between night cough and wheeze in asthma ${ }^{7}$ and the interrelations of various measures of night time severity. The relationship between indices of night severity and daytime pulmonary function status, recently reported for adults, ${ }^{8}$ has similarly received little attention in children.

This study investigated the interrelation of night cough, overnight arterial oxygen saturation $\left(\mathrm{SaO}_{2}\right)$, evening and morning peak flow, and the relation of each to day time indices of lung function in a group of children about to be discharged from hospital after an acute attack of asthma.

\section{Patients}

Twenty two patients were recruited from the paediatric wards of the Leicester Royal Infirmary over an 18 month period. Those eligible for the study were schoolchildren (5-14 years) admitted for at least two nights with an acute asthmatic attack. As most asthma admissions in this hospital stay only one night, selection was biased towards those with more severe or prolonged attacks for whom hospital stay (including the days of admission and discharge) varied from three to five days (mean 3.5). The availability of staff and equipment were further constraints on patient selection. Thus if two or more children were suitable for study on the same night, one was chosen at random. The study was approved by the Leicester Health Authority ethical committee.

The children selected had a history of episodic wheezing and had demonstrated an increase in peak flow exceeding $15 \%$ after inhalation of a $\beta_{2}$ agonist. On admission to hospital they had extremely low or unrecordable peak flow readings but were competent at using a peak flow meter when well. Children entered the study on the day before planned discharge. Participation did not influence clinical management or decisions about the timing of discharge.

All had been treated with two hourly nebulised $\beta_{2}$ agonists and oral prednisolone $(2 \mathrm{mg} / \mathrm{kg} /$ day $)$ at the time of admission to the study. Two children also received intravenous aminophylline and hydrocortisone when the initial response to treatment was poor. When suitable patients had been identified, the nature of the study was explained to the parents and the child and informed consent was obtained. Details of the current admission and past history were obtained from interview with the parents and from previous medical records (table 1). Most attended the hospital as outpatients on a regular basis but five had not been admitted previously. At the other extreme, one 7 year old child had 25 documented asthma admissions, including four in the previous 12 months. All but one had received regular treatment at home and 15 were on prophylactic sodium cromoglycate or beclomethasone.

\section{Methods}

Lung function tests were carried out on the afternoon before overnight monitoring. Lung volume and airway resistance were measured by whole body plethysmography (Bodytest, Jaeger Ltd), maximum expiratory flow rates by an electronic spirometer (Gould) and peak flow with a Wright peak flow meter. All measure- 
Table 1 Details of study children

\begin{tabular}{ll}
\hline Age (years) & $9 \cdot 0$ \\
Mean & $3 \cdot 0$ \\
SD & $5 \cdot 2-14 \cdot 4$ \\
Range & \\
Height (m) & $1 \cdot 31$ \\
$\quad$ Mean & $0 \cdot 17$ \\
SD & $15: 7$ \\
Male:female ratio & \\
Highest respiratory rate & 48 \\
Mean & 12 \\
SD & $32-80$ \\
Range & 2 \\
Intravenous medication & \\
Length of stay in days & \\
Mean & $3 \cdot 5$ \\
Range & $3-5$ \\
Previous admissions & \\
Mean & \\
SD & $4 \cdot 4$ \\
Range & $6 \cdot 3$ \\
Regular medication & $0-25$ \\
Nil & \\
$\beta_{2}$ agonist & 1 \\
Sodium cromoglycate & \\
Inhaled steroid & \\
Symptoms at home & \\
Intermittent & \\
Continuous & 10 \\
\hline
\end{tabular}

ments were made before and 10-15 minutes after inhalation of salbutamol. The results (except residual volume (RV) as a ratio of total lung capacity (TLC) were converted to perecentage of the predicted values for height using published data on normal children ${ }^{9-13}$ to facilitate comparison between children of different ages. Daytime (awake) $\mathrm{SaO}_{2}$ was measured in the late afternoon over at least $\mathbf{1 0}$ minutes, with the child resting and supine using the system employed for the night study.

Clinical examinations were carried out by one clinician (EWH) before each overnight monitoring and again the next morning. Pulse rate, respiration rate, blood pressure, and pulsus paradoxus were recorded. A subjective score (0-2) was given for hyperinflation, tracheal tug, intercostal recession, audible wheeze, and auscultatory wheeze. Peak flow was also measured at these times.

Overnight monitoring was done in a quiet cubicle adjacent to the ward area. A Biox 3700 Pulse Oximeter attached to a Squirrel data logger (SQ32-3V/IL/3D, Grant Instruments Cambridge Ltd) monitored $\mathrm{SaO}_{2}$ and pulse rate (averaged over three seconds) at one minute intervals. A finger probe was secured firmly using adhesive tape and remained in situ overnight. The stored overnight data were examined to exclude any artefact due to a poor probe position and body movement. As the pulse rate was also recorded, this consisted of excluding $\mathrm{SaO}_{2}$ readings associated with a sudden inappropriate fall in pulse rate. These exclusions comprised only a small fraction of each overnight record, and although these points were excluded from analysis, the large number of data points through the night meant that they would have had little discernible effect on the mean $\mathrm{SaO}_{2}$. The results were analysed to give mean $\mathrm{SaO}_{2}$ and percentage time $<90 \% \mathrm{SaO}_{2}$.

Night cough was recorded on a tape recorder using a cough monitor with a voice activated switch set at a selected trigger level, as described previously. ${ }^{5}$ The two microphones were mounted on freestanding tripods placed on either side of the bed, pointing towards the subject and adjusted so that coughing from any part of the bed would activate the switch. A BBC computer and specially designed programme facilitated analysis by giving the number of 10 second 'epochs' during which coughing occurred. This method gave qualitatively similar results to counting individual coughs. The extraneous noises that occasionally occurred were excluded from the analysis by listening to each tape during the analysis procedure. These were easily detected and there was no evidence that they disturbed the children or provoked them to cough.

\section{Results}

The children were discharged home on the day after the overnight study, except for one who continued on nebulised salbutamol for a further 24 hours before discharge. Treatment with inhaled bronchodilator and oral prednisolone continued at discharge. Other medication was continued as before admission.

\section{NIGHT TIME MEASUREMENTS}

Table 2 summarises the results for the night time measures of asthma severity. The number of coughing epochs throughout the night varied from 1 to 156 with a median value of 39.5 and a mean of $49 \cdot 3$. The data were normalised by taking $\log _{\mathrm{e}}$ values.

The mean overnight $\mathrm{SaO}_{2}$ for the group as a whole was $91.3 \%$ and the mean percentage time less than $90 \%$ saturation was $35 \cdot 9 \%$. Seven children had $\mathrm{SaO}_{2}<90 \%$ for more than $50 \%$ of the time and three for more than $90 \%$ of the time. The difference between maximum and minimum overnight $\mathrm{SaO}_{2}$ recordings ranged from 5 to $21 \%$ with a mean of $14.5 \%$. On examining the individual $\mathrm{SaO}_{2}$ traces, baseline values were remarkably constant during the night, with no evidence of change with time and no evidence of prolonged periods of desaturation. Figure 1 shows a typical overnight oxygen saturation trace and figure 2 a comparison of two methods of presenting the data obtained.

The mean percentage of predicted peak flow for evening and morning for the cases where paired results were recorded was $69 \%$ and $67 \%$ respectively (SE of the mean difference $=5 \cdot 0$ ). Six children out of 16 and five out of 19 studied in the evening and morning respectively had a peak flow $<80 \%$ of the predicted value. The mean peak flow variability (expressed as the

Table 2 Night time measures of asthma severity

\begin{tabular}{lcl}
\hline Parameter & Mean & Range \\
\hline Coughing epochs & $49 \cdot 3$ & $1-156$ \\
Overnight mean $\mathrm{SaO}_{2}$ (\%) & $91 \cdot 3$ & $82-98$ \\
Evening PF as \% of predicted value & $72 \cdot 3$ & $31-129$ \\
Morning PF as \% of predicted value & $66 \cdot 7$ & $27-110$ \\
PF variability \% & $-7 \cdot 1$ & -71 to +38 \\
Evening clinical score & $3 \cdot 2$ & $0-7$ \\
Morning clinical score & $2 \cdot 4$ & $0-5$
\end{tabular}

Peak flow (PF) variability is calculated as (PFpm-PFam)/ PFpm $\times 100$. 


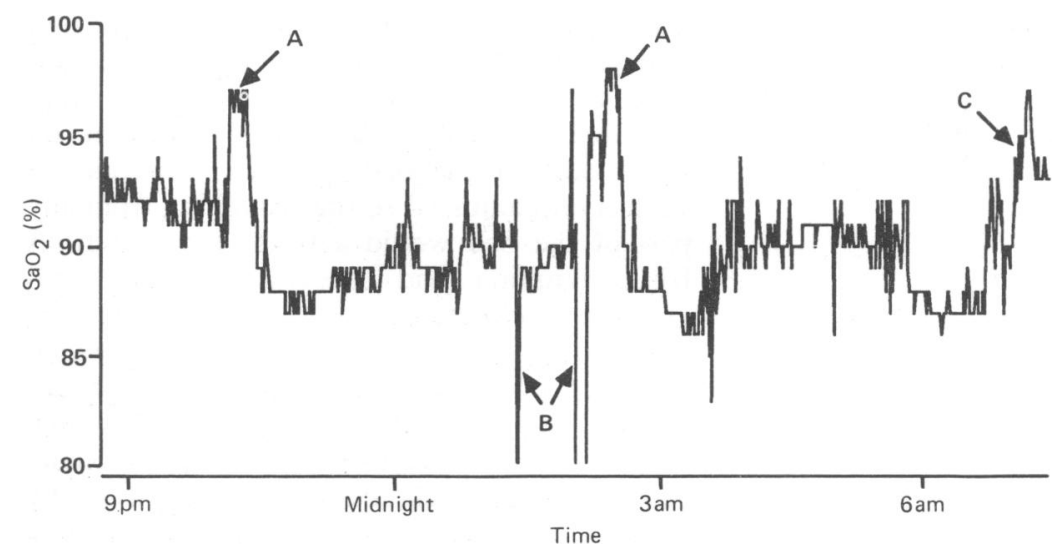

Figure 1 Typical overnight SaO, trace. Mean saturation for this case was $90 \%$. At points marked $A$, nebulised salbutamol was given. At $B$, the drop in saturation was associated with a sudden drop in pulse rate, indicating poor connection of the finger probe. At $C$, a further nebuliser was given and the child woke up. Recordings at all these points were excluded from analysis. percentage change in peak flow between evening and morning) was $-7 \cdot 1 \% \quad(\mathrm{SD}=36$, prebronchodilator data).

The clinical assessment in the evening (maximum score $=10$ ) was mean $3 \cdot 2$, and the next morning was mean $2 \cdot 3$ (SE of the mean difference $=0 \cdot 32, \mathrm{p}<0 \cdot 05$ ).

CORRELATION OF NIGHT TIME VARIABLES

The data are shown in table 3. There was a significant negative correlation between overnight $\log _{\mathrm{e}}$ cough and $\mathrm{SaO}_{2}(\mathrm{r}=-0.564, \mathrm{p}=0.01$, see fig 3) but no correlation between $\log _{e}$ cough and any of the peak flow measures. There was a significant correlation between mean overnight $\mathrm{SaO}_{2}$ and both evening and morning peak flow.

Neither evening nor morning clinical scores correlated with $\log _{e}$ cough, night $\mathrm{SaO}_{2}$ or peak flow.

\section{NIGHT TIME AND DAYTIME MEASUREMENTS}

The mean daytime $\mathrm{SaO}_{2}$ was $93.0 \%$ (range 89.0-96.5\%).

Table 4 gives the results of lung function tests. They show varying degrees of hyperinflation and expiratory airflow limitation within the group.

There was a small but not significant difference between daytime and overnight $\mathrm{SaO}_{2}$

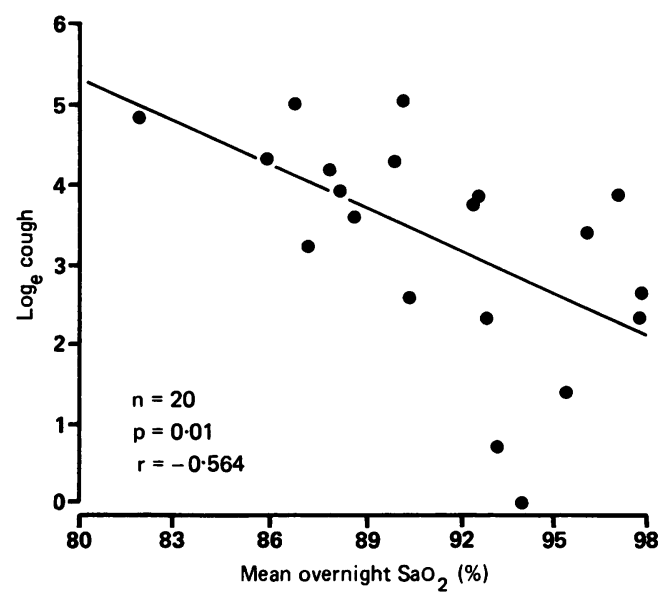

Figure 3 Comparison of overnight cough and overnight $\mathrm{SaO}_{2}$.

Table 4 Results of lung function tests

\begin{tabular}{|c|c|c|c|c|c|c|}
\hline \multirow[b]{2}{*}{ Parameter } & \multicolumn{3}{|c|}{ Before bronchodilator } & \multicolumn{3}{|c|}{ After bronchodilator } \\
\hline & No & Mean & Range & No & Mean & Range \\
\hline 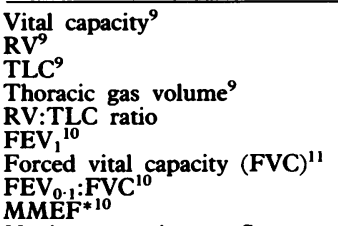 & $\begin{array}{l}17 \\
14 \\
19 \\
20 \\
14 \\
18 \\
15 \\
18 \\
13\end{array}$ & $\begin{array}{r}74 \\
154 \\
96 \\
105 \\
41 \\
72 \\
85 \\
75 \\
53\end{array}$ & $\begin{array}{l}31-124 \\
72-261 \\
70-124 \\
69-140 \\
19-66 \\
34-135 \\
47-133 \\
57-96 \\
18-108\end{array}$ & $\begin{array}{l}17 \\
16 \\
18 \\
20 \\
16 \\
19 \\
15 \\
19 \\
14\end{array}$ & $\begin{array}{r}78 \\
143 \\
95 \\
101 \\
38 \\
74 \\
91 \\
91 \\
74 \\
52\end{array}$ & $\begin{array}{l}42-124 \\
71-214 \\
64-125 \\
66-129 \\
19-60 \\
42-135 \\
53-137 \\
57-94 \\
17-105\end{array}$ \\
\hline $\begin{array}{l}\text { Maximum expiratory flow: } \\
50 \% \text { FVC } \\
25 \% \text { FVC'12 } \\
60 \% \text { TLC } \\
\text { Peak flow } \\
\text { Airway resistance }\end{array}$ & $\begin{array}{l}15 \\
13 \\
16 \\
21 \\
21\end{array}$ & $\begin{array}{r}55 \\
43 \\
29 \\
72 \\
231\end{array}$ & $\begin{array}{l}23-118 \\
10-101 \\
74-89 \\
41-124 \\
105-504\end{array}$ & $\begin{array}{l}15 \\
14 \\
15 \\
21 \\
21\end{array}$ & $\begin{array}{r}57 \\
39 \\
39 \\
78 \\
176\end{array}$ & $\begin{array}{r}25-118 \\
7-102 \\
2-89 \\
48-129 \\
63-274\end{array}$ \\
\hline
\end{tabular}

Results are expressed as percentage of the predicted value for height based on published reference ranges, except RV:TLC where the ratio is given as a percentage 
Table 5 Pearson correlation coefficients of night time with daytime measures of asthma severity

\begin{tabular}{|c|c|c|}
\hline & $\log _{e}$ cough & $\begin{array}{l}\text { Mean night } \\
\mathrm{SaO}_{2}\end{array}$ \\
\hline $\begin{array}{l}\text { Mean daytime } \mathrm{SaO}_{2} \\
\text { Peak flow during day } \\
\text { RV:TLC } \\
\text { Maximum expiratory flow: } \\
60 \% \text { TLC } \\
50 \% \text { VC } \\
25 \% \text { VC } \\
\text { Airway resistance }\end{array}$ & $\begin{array}{l}-0 \cdot 078 \\
-0 \cdot 361 \\
-0 \cdot 450^{*} \\
-0 \cdot 378 \\
-0 \cdot 225 \\
-0 \cdot 498 \dagger \\
0 \cdot 245\end{array}$ & $\begin{array}{c}-0.585^{*} \\
0.520^{*} \\
-0.711^{*} \\
0.720^{*} \\
0.328 \\
0.330 \\
-0.236\end{array}$ \\
\hline
\end{tabular}

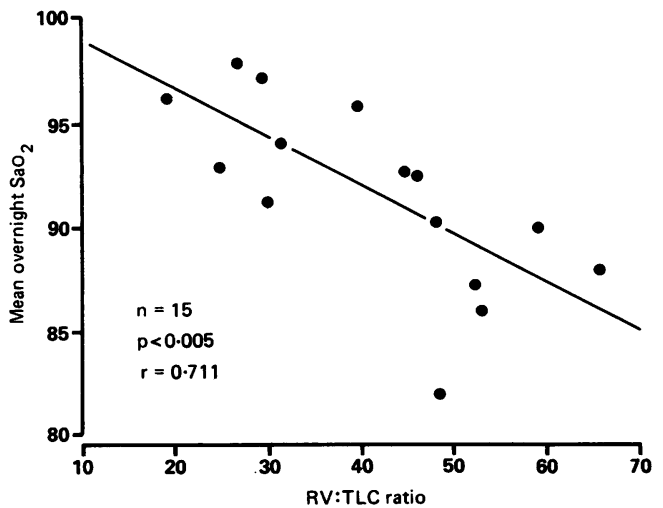

Figure 4 Overnight $\mathrm{SaO}_{2}$ compared with the degree of hyperinflation $(R V: T L C)$.

(mean fall $=1 \cdot 2 \%$. SEM $=0.74, \mathrm{p}<0.08$ ) with a significant correlation between the two variables $(\mathrm{r}=0.585, \mathrm{p}<0.01$, table 5). There was no correlation between $\log _{e}$ cough and daytime $\mathrm{SaO}_{2}$.

The overnight $\mathrm{SaO}_{2}$ correlated best with presalbutamol measures of RV:TLC (fig 4) and the maximum expiratory flow at $60 \%$ of TLC and to a lesser extent with peak flow. There was no association of $\mathrm{SaO}_{2}$ with maximum expiratory flow at $50 \%$ or at $25 \%$ of vital capacity.

Less marked correlations were found between $\log _{e}$ cough and the results of lung function tests. $\log _{e}$ cough correlated with RV:TLC but not with the maximum expiratory flow at $60 \%$ of TLC or with peak flow. The evening and morning clinical scores also correlated with this hyperinflation $(p<0.02$, $\mathrm{r}=0.605$; and $\mathrm{p}<0.005, \mathrm{r}=0.693$ respectively) but not with expiratory flow at $60 \%$.

\section{Discussion}

In this group of asthmatic children, studied before discharge from hospital, there was a high prevalence of pulmonary function abnormalities both by day and night, with wide variation in severity. Although there was an inverse relation between $\log _{e}$ cough and $\mathrm{SaO}_{2}$ measured overnight, several children coughed frequently despite relatively normal $\mathrm{SaO}_{2}$ concentrations. Evening and morning peak flow correlated with $\mathrm{SaO}_{2}$ but not with $\log _{e}$ cough, and peak flow variability did not correlate with either. Clinical scores showed no relationship with any measure of night time asthma. Among daytime measures the degree of hyperinflation correlated best with the night time variables, particularly $\mathrm{SaO}_{2}$.
These results probably reflect the situation for most children at the time of discharge from hospital after a moderate to severe attack of asthma, as participation in the study had not influenced clinical decisions.

The median cough score $(39 \cdot 5$, range $1-156)$ is much higher in this study than that reported for asthmatic children of similar age with persistent night cough studied at home, in whom median cough score was 6.6 episodes per night (range 0-272). ${ }^{5}$ It is also higher than the reported mean value of 14.6 episodes in adult patients with chronic bronchitis and persistent cough, ${ }^{14}$ although a different definition of a coughing episode was used. Higher median cough counts were obtained for adults admitted with acute respiratory problems ${ }^{15}$ but comparisons are difficult as these authors counted individual coughs.

This group also showed a high prevalence of hypoxaemia with eight out of 22 children having mean $\mathrm{SaO}_{2}<90 \%$. Our method of collecting the $\mathrm{SaO}_{2}$ data used lower sampling rates than other studies and did not allow us to look for dips in saturation associated with coughing bouts, but studies in adult patients suggest that dips in $\mathrm{SaO}_{2}$ are strongly correlated with sleep state and not at all with episodes of coughing. ${ }^{14}$ Coughing often involves quite extensive body movements so dips during coughing may be difficult to interpret. $\mathrm{SaO}_{2}$ normally decreases slightly at night and that fall is larger in asthmatic children. ${ }^{16} 17$ The mean range of $\mathrm{SaO}_{2}$ through the night for our patients was $14.5 \%$, which compares with $5 \cdot 1 \%$ and $6 \cdot 8 \%$ for clinically stable asthmatics ${ }^{16} 17$ and $8.9 \%$ for those on suboptimal treatment. ${ }^{17}$ All the individual measurements of $\mathrm{SaO}_{2}$ were associated with a consistent recording of the pulse and therefore probably reflect a true increase in the variability of $\mathrm{SaO}_{2}$ in this group. Although the mean saturation was below $90 \%$ in eight cases, all the children were considered fit for discharge the next day.

Evening and morning peak flow were both low with $38 \%$ and $26 \%$ of children respectively having a peak flow $<80 \%$ of that predicted. Mean values were lower in the morning than in the evening, but this effect was not significant. The evening and morning readings and the peak flow variability showed wide variation within the group.

Clinical scoring systems ${ }^{1819}$ are partly subjective and difficult to validate, but do attempt to quantify the degree of clinical severity. The relatively low scores seen in this study reflect the fact that the children were considered ready for discharge-a condition of entry to the study. Clearly the scores obtained were poor indicators of functional severity in the children studied.

There was a correlation between overnight $\log _{\mathrm{e}}$ cough and mean overnight $\mathrm{SaO}_{2}$. Children with low $\mathrm{SaO}_{2}$ had high cough counts but the converse was not necessarily true (fig 3 ). In a study of night cough in asthmatic children, Thomson et al found that most episodes occurred within two hours of going to bed or shortly before waking. ${ }^{5}$ Sleep status was not recorded in this study but electroencephalographic studies 
in coughing adults have shown that $85 \%$ of night coughing occurs during wakefulness and that coughing rarely wakes patients from sleep. ${ }^{14}$ There was no evidence of hypoxaemia at the beginning or end of the night in this study, which makes a causal relationship between cough and hypoxaemia unlikely. The distribution of cough receptors in the airways and lungs has been the subject of a recent review. ${ }^{20}$ It seems probable that during acute attacks of asthma the mechanisms responsible for airway narrowing and cough may to some extent overlap. There was, however, no association between $\log _{e}$ cough and peak flow. Cough occurs mainly at the beginning and end of sleep, ${ }^{5}$ whereas the nadir of peak flow is at around 4 am. $^{6} 21$ This may reflect differences between the pulmonary mechanisms in cough and airflow limitation. It has been shown that increased bronchial responsiveness is present in adult asthmatics whose predominant symptom is cough ${ }^{22}$ or marked variability in peak flow. ${ }^{8}$ Conversely, there is evidence that children with chronic cough have similar family histories and atopic characteristics to those of children with asthma, ${ }^{23}$ and bronchial hyperresponsiveness which responds to theophylline. ${ }^{24}$ These studies suggest that in such cases cough is best treated with bronchodilators. ${ }^{22}$

There was a correlation between evening and morning peak flow and nocturnal $\mathrm{SaO}_{2}$ though the behaviour of individuals was not predictable. Previous studies ${ }^{617}$ in asthmatic children between acute attacks have shown no correlation between mean nocturnal $\mathrm{SaO}_{2}$ or $\mathrm{SaO}_{2}$ drop and degree of obstruction measured as forced expiratory volume in one second $\left(\mathrm{FEV}_{1}\right)$ but one study ${ }^{17}$ showed a correlation between maximum fall overnight of $\mathrm{SaO}_{2}$ and maximum change in $\mathrm{FEV}_{1}$. Hypoxaemia persisting after reversal of airflow obstruction merely reflects persisting ventilation/perfusion imbalance in the lungs.

The clinical assessment did not predict either night cough or $\mathrm{SaO}_{2}$. Clinical indices of severity correlate poorly if at all with arterial oxygen tension in the acute attack. ${ }^{18}$ Our clinical assessments underestimated night time functional severity to a considerable extent.

In general, both overnight $\log _{e}$ cough and $\mathrm{SaO}_{2}$ showed similar correlations with day time tests of lung function, but the relationship with night $\mathrm{SaO}_{2}$ was always closer. In contrast to adult asthmatics with prominent cough ${ }^{22}$ there was little evidence in this study that those with more coughing had greater large airway involvement (as measured by peak flow or airway resistance). Increasing RV:TLC was the best single marker of poor night time function, correlating well with high cough rates and a low $\mathrm{SaO}_{2}$. It is a measure of hyperinflation and, by implication, peripheral airways obstruction, which in turn influences ventilation/perfusion ratios. However, the association is not necessarily causal and in the case of cough is unlikely to be so. In children, the normal range for the hyperinflation ratio ${ }^{25}$ is $22 \%+8 \%$ and only two in this study group were within the normal range. This ratio also correlated with the clinical score, in contrast to the findings in an out- patient study which showed no association between clinical examination and lung function abnormalities. ${ }^{26}$ Although flow rates at low lung volumes $(50 \%$ and $25 \%$ of vital capacity) showed no association with $\mathrm{SaO}_{2}$, once this was corrected for the degree of hyperinflation $(60 \%$ of TLC) a significant correlation emerged. Thus, reduced flow rates were also a good marker for low nocturnal $\mathrm{SaO}_{2}$ but only if corrected for the degree of hyperinflation.

As cough, expiratory airflow limitation, and hypoxaemia are all features of severe asthma, some correlation between these variables is to be expected. Night cough is certainly a feature of severe dysfunction in asthma, but can be a persistent symptom in its absence. Its interrelationship with wheeze needs further investigation.

We are indebted to Fisons PLC who gave generous support for DMH.

1 Hetzel MR, Clark TJH. Comparison of normal and asthmatic circadian rythms in peak expiratory flow rate. Thorax circadian rythm

2 Hetzel MR, Clark TJH, Branthwaite MA. Asthma: analysis of sudden deaths and ventilatory arrests in hospital. $B M \mathcal{F}$ 1977;1:808-11.

3 Cochrane GM, Clark TJH. A survey of asthma mortality in patients between ages 35 and 64 in the greater London hospitals in 1971. Thorax 1975;30:300-5.

4 Archer LNJ, Simpson H. Night cough counts and diary card scores in asthma. Arch Dis Child 1985;60:473-4.

5 Thomson AH, Pratt C, Simpson H. Nocturnal cough in asthma. Arch Dis Child 1987;62:1001-4.

6 Soutar CA, Carruthers M, Pickering CAC. Nocturnal asthma and urinary adrenaline and noradrenaline excretion. Thorax 1977;32:677-83.

7 Editorial. Cough and wheeze in asthma: are they interindependent? Lancet $1988 ; \mathrm{i}: 447-8$.

8 Martin RJ, Cicutto LC, Ballard RD. Factors related to the nocturnal worsening of asthma. Am Rev Respir Dis nocturnal wors

9 Zapletal A, Paul T, Samanek M. Pulmonary elasticity in children and adolescents. F Appl Physiol 1976;40:953-61.

10 Zapletal A, Paul T, Samanek M. Die Bedeutung heutiger Methoden der Lungenfunctions-diagnostik zur Feststellung einer Obstruction der Atemwege bei Kindern und Jungendlichen. Z Erkr Atmungsargane 1977;149:343-71

11 Zapletal A, Samanek M, Paul T. Upstream and total airway conductance in children and adolescents. Bull Eur Physio pathol Respir 1982;18:31-7.

12 Solymar L, Aronsson P-H, Bake B, Bjure J. Nitrogen single breath test, flow-volume curves and spirometry in healthy children 7-18 years of age. Eur $\mathcal{F}$ Respir Dis 1980;61: 275-86.

13 Cogswell JJ, Hull D, Milner AD, Norman AP, Taylor B. Lung function in childhood. 1 . The forced expiratory volumes in healthy children using a spirometer and reverse plethysmograph. Br f Dis Chest 1975;69:40-50.

14 Power JT, Stewart IC, Connaughton JJ, et al. Nocturnal cough in patients with chronic bronchitis and emphysema. cough in patients with chronic bronchitis
Am Rev Respir Dis 1984;130:999-1001.

15 Loudon RG, Brown LC. Cough frequency in patients with oudon RG, Brown LC. Cough frequency in patients with
respiratory disease. Am Rev Respir Dis 1967;96:1137-41.

16 Chipps BE, Mak H, Schuberth KC, et al. Nocturnal oxygen saturation in normal and asthmatic children. Pediatrics 1980;65:1157-60.

17 Smith TF, Hudgel DW. Arterial oxygen saturation during sleep in children with asthma and its relation to obstruction and ventilatory drive. Pediatrics 1980;66:746-51.

18 McKenzie SA, Edmunds AT, Godfrey S. Status asthmaticus in children. Arch Dis Child 1979;54:581-6.

19 Storr J, Barrell E, Barry W, Lenney W, Hatcher G. Effect of a single oral dose of prednisolone in acute childhood asthma. Lancet 1987;i:879-82.

20 Fuller RW, Jackson DM. Physiology and treatment of cough. Thorax 1990;45:425-30.

21 Barnes P, Fitzgerald G, Brown M, Dollery C. Nocturnal asthma and changes in circulating epinephrine, histamine and cortisol. $N$ Engl $\mathcal{F}$ Med 1980;303:263-7.

22 McFadden ER Engl acute attacks of bronchial asthma. N Engl $\mathcal{Y}$ Med 1975;292: 555-9.

23 Lewis HM, Haeney M, Jeacock J, Thomas H. Chronic cough in a hospital population; its relationship to atopy and in a hospital population; its relationship to atopy and
defects in host defence. Arch Dis Child 1989;64:1593-8.

24 Cloutier MM, Loughlin GM. Chronic cough in children: manifestation of airway hyperreactivity. Pediatrics 1981; manifest

25 Weng $T-\dot{R}$, Levison $H$. Standards of pulmonary function in children. Am Rev Respir Dis 1969;99:879-94.
chist

26 Konig P, Rejent A. Subjective and objective means of assessing cystic fibrosis and asthma. Ann Allergy 1982;49. 86-92. 